\title{
Atopic Dermatitis: A Patient and Dermatologist's Perspective
}

Mylène Berruyer $\cdot$ Juliette Delaunay

Received: January 7, 2021

(C) The Author(s) 2021, corrected publication 2021

\begin{abstract}
This article has been co-authored by a patient with atopic dermatitis (AD) and her consulting dermatologist who is based at the University Hospital in Angers, France. Here they discuss the patient's experiences and difficulties with $\mathrm{AD}$, as well as strategies that can help a patient in this situation. The patient describes the history of her illness and the difficulties encountered, particularly in terms of quality of life. She describes the various treatments she has received, mainly based on topical corticosteroids, and tells of her satisfaction at being treated today at the University Hospital. The healthcare team there is supportive and reassuring and she is receiving a systemic medication that has successfully reduced and controlled her AD symptoms. The physician describes the main characteristics of $\mathrm{AD}$, and then reviews this case of chronic eczema with topographical localisations on the hands, head and neck and diffuse flares. Rapid resolution of the flares on the patient's hands and face, which were having a strong impact on mood, was achieved
\end{abstract}

Electronic supplementary material The online

version of this article (https://doi.org/10.1007/s13555021-00497-w) contains supplementary material, which is available to authorized users.

J. Delaunay $(\varangle)$

Service de Dermatologie, Centre Hospitalier Universitaire d'Angers, 49000 Angers, France

e-mail: juliette.delaunay@chu-angers.fr

M. Berruyer

Angers, France by treatment with systemic ciclosporin and topical corticosteroids. In 6 months, treatment with dupilumab will be planned to avoid ciclosporininduced adverse effects on kidney function. The pivotal roles of therapeutic education as an adjunct to conventional therapy, a good patient-physician relationship with consideration of the patient's personal preferences, and treatment objectives are highlighted in this perspective piece.

\section{PLAIN LANGUAGE SUMMARY}

This article has been co-authored by a French patient who has had atopic dermatitis (eczema, AD) since childhood and her dermatologist, a French healthcare professional based in a university hospital in Angers. AD is caused by a genetic variation that affects the skin's ability to protect against bacteria, irritants and allergens. In people with $\mathrm{AD}$, environmental factors make the skin red and itchy. AD can occur at any age; it most often begins before 5 years of age and may persist into adolescence and adulthood. $\mathrm{AD}$ signs and symptoms vary widely, and the disease may be accompanied by asthma and allergies. $\mathrm{AD}$ is long lasting (chronic) and, even if treatment is successful, signs and symptoms may return (flare) periodically. The patient describes her personal experience, including how the discomfort from the $\mathrm{AD}$ on her face and 
hands affected her daily activities and sleep. She talks about having to try various treatments, including home remedies, over the years to control $\mathrm{AD}$ and relates her frustration when experiencing symptoms. Now she is being monitored by a healthcare team in a French university hospital that gives her full care and support. As a result, she is now receiving a systemic medication that reduces and controls the AD symptoms and she is very satisfied with her care. The dermatologist notes that this patient's experience is a common clinical picture of $\mathrm{AD}$ in adults, and discusses how the patient was treated and how the treatment will evolve over time. The dermatologist emphasises the importance of a good patient-physician relationship for successful AD management. This should be based on confidence and empathy, and consider the patient's expectations, personal preferences and treatment objectives. Therapeutic education (educational programs, video training and workshops) is pivotal as an adjunct to conventional therapy.

Keywords: Atopic dermatitis; Dermatology; Eczema; Patient's perspective

\section{Key Summary Points}

This article has been co-authored by a patient with atopic dermatitis and her consulting dermatologist.

The patient describes her personal experience, the history of her illness, the various treatments she has received and the difficulties encountered.

The physician describes the main characteristics of atopic dermatitis, and reviews this case of chronic eczema and how the patient was given care at the hospital.

The pivotal roles of therapeutic education as an adjunct to conventional therapy, a good patient-physician relationship with consideration of the patient's personal preferences, and treatment objectives are highlighted.

\section{DIGITAL FEATURES}

This article is published with digital features, including a summary slide and talking head video abstract, to facilitate understanding of the article. To view digital features for this article go to https://doi.org/10.6084/m9.figshare.13614314.

\section{PATIENT'S PERSPECTIVE}

I am 32 years old, single, and I work as an agricultural engineer in Angers, France. Atopic dermatitis (AD) has been part of my life for as long as I can remember. From an early age, I was aware of the need to live with this disease. As a child, my mother taught me how to lead a healthy life: I learnt how to apply creams, and how to carefully follow the application schedule. Unfortunately, I am not the only one in my family with this disease, as my twin sister and my mother have $\mathrm{AD}$ as well. $\mathrm{AD}$ is part of our everyday family life and is a regular topic of discussion. Over the years, I have had AD patches on my face, around my eyes and mouth, on my neck, and in the crease of my elbows. In more recent years, the eczema patches have mainly been located on my hands.

Living day to day with $\mathrm{AD}$ is not easy. It is particularly hard when your face is affected, because people look at you differently. AD on the hands is painful all the time and the slightest stress can make it worse. The itching from $\mathrm{AD}$ is constant and it is difficult not to scratch. When you do, you feel like you are being watched, and sometimes people make comments.

Nothing happens normally with AD. You have to use cream daily, wear rubber gloves when washing dishes and cooking, and pay attention to the clothes you are wearing. I have never liked showing my hands, and using nail polish or wearing rings or bracelets was out of the question. It has even been difficult or painful to shake hands, which is an important part of professional relationships in France. When you have eczema, the itching disturbs your sleep, which makes you tired and irritable. Before you go to bed, you have to put on cream 
and the doctors told me to wear gloves in bed, which I hate doing. Handwashing has to be kept to a minimum, and this is not always possible in everyday life. All these details sound minor when taken separately, but together they have simply ruined my life.

Over the years, I have seen many dermatologists who have investigated all possible causes, including allergy. They often referred to stress as the cause, and mainly prescribed topical corticosteroids. I have been applying creams for so long, and none of them really work $100 \%$ for me. I have used various classes of topical corticosteroids, as well as topical tacrolimus, but every time I stopped treatment the eczema came back. The only result in the long term was the spread of patches to a different part of my body. One dermatologist treated me with phototherapy, and the results were very encouraging after the first session, but much less impressive after the second session. Moreover, when you feel that nothing is fully effective, you may also try other alternatives. For example, I even tried seeing a hypnotist at one point, but, unfortunately, it was not very successful.

I had an episode of strong flares during the first lockdown due to the COVID-19 pandemic in 2020. I think this was related to stress, because I had avoided the recommendations to wash my hands more often, use hand-sanitising gels and wear facemasks. I had almost lost all hope. Fortunately, my former dermatologist referred me to the University Hospital in Angers, and I met Dr. Delaunay for the first time on 29 May 2020. The first appointment at the hospital was a revelation for me. Dr. Delaunay took the time to explain $\mathrm{AD}$ to me as nobody had ever done before. She introduced me to a nurse, and together they spent time examining every $\mathrm{AD}$ patch very carefully. They were sensitive to my emotional and physical state, they listened carefully to my expectations, and sometimes even anticipated my questions. This is the first time in my life that a healthcare professional explained the right method to apply the creams. They also gave me tips and tricks to manage my disease, which I have put into practice and they work! They also gave me addresses of French websites with more information and suggested that I join a discussion group. From the first consultation, I have been able to contact either of them by email, and always receive quick answers or a new appointment. This close follow-up of the medical staff is new for me, and a true godsend, because I am no longer left to manage this disease by myself.

Of course, I have always known I will never fully recover from $\mathrm{AD}$, which sometimes made me feel bad. But now I know that treatments can control the symptoms of the disease and could help achieve remission. At the first appointment at the University Hospital, I was given systemic treatment with ciclosporin. This is the first time I have been prescribed a systemic medicine and not just creams. The effects were very rapid; the lesions began to heal immediately and most of the open wounds had disappeared 4 days after starting treatment. Today, I feel much better, almost as if I am living again. I have even started painting my nails!

There are renal side effects associated with the use of ciclosporin, so I know that it cannot be a long-term treatment. In fact, my recent blood tests results showed elevated creatinine levels so the dose of ciclosporin was reduced. Nevertheless, I am confident about the future because I have been told that there are therapeutic alternatives that I can benefit from.

Based on my experience, I have at least three messages of hope for all patients suffering from AD. Firstly, medicine is moving forward, and there are now treatments that can reduce $\mathrm{AD}$ symptoms to the point where you can forget you have AD. Secondly, I have been lucky enough to get support from a wonderful clinical team. There are many specialists familiar with $\mathrm{AD}$ who know how to treat it; they are aware of our suffering and are supportive and reassuring. Thirdly, it is really important to stay positive and confident in the future as we, patients with $\mathrm{AD}$, may benefit from treatments that considerably improve our lives. 


\section{DERMATOLOGIST'S PERSPECTIVE}

I am a dermatologist and allergologist working at the University Hospital in Angers, France. I saw Ms. Berruyer for the first time at the end of May 2020, when she presented with a clear clinical picture of $\mathrm{AD}$.

$\mathrm{AD}$ is not a homogeneous disease; it comprises several phenotypes with different mechanisms. The pathophysiology of $\mathrm{AD}$ is complex and relies on two key factors, an alteration of the cutaneous barrier and a disturbance of the innate and adaptive immune systems [1]. The alteration of the epidermal barrier function is of genetic origin, which explains why multiple cases can be found in the same family, but it also relates to exogenous factors (in particular, environmental factors). AD is a polygenic disease. Study of the human genome has identified 31 overexpressed loci in patients with $\mathrm{AD}$, belonging to two groups of genes involved in the pathophysiology of epithelial barriers, including the filaggrin gene [2], and genes involved in the immune response, particularly in adaptive immunity involving type 2 helper T cells, which generate interleukin (IL)-4, IL-5 and IL-13 [3, 4].

The prevalence of $\mathrm{AD}$ is probably underestimated and is increasing steadily. In France, AD is present in $10 \%$ of children and $4 \%$ of adults [5]. AD has a paediatric onset and two-thirds of cases begin before the age of 1 year. This means that, when the patient finally consults a specialist dermatologist, the disease has often been evolving for several years.

$\mathrm{AD}$ is associated with substantial burden and comorbidities [6], including a range of allergic conditions (food allergy, asthma, allergic rhinitis, allergic conjunctivitis and eosinophilic oesophagitis), suggesting both cutaneous and systemic immune activation. There is a strong pattern of immune activation in peripheral blood in $\mathrm{AD}$, and a propensity for patients to develop both skin and systemic infections. Independent of age, there is a greater prevalence of depression, anxiety and suicidal ideation among individuals with $\mathrm{AD}$, which is often related to the visible manifestations of the disease [7]. The disease negatively impacts patient quality of life [8], with sleep disturbance a major causative factor. Signs of attention-deficit/hyperactivity disorder are common in children with AD [9].

When I first see a patient with $\mathrm{AD}$, I take the time to inform him/her about the disease and to explain the principles of topical management. Therapeutic education should always be an adjunct to conventional therapy and can be done through educational programs, video training or nurse-led workshops (Table 1).

Conventional therapies include a variety of topical treatments: emollients, topical corticosteroids and tacrolimus, and systemic treatments may be considered when topical anti-inflammatory therapy is no longer sufficient. Three systemic treatments have marketing authorisation in France: phototherapy, systemic immunosuppressive treatment with ciclosporin, and dupilumab, which is a biological agent targeting the type $2 \mathrm{~T}$ cell pathway $[10,11]$.

At the time of her first consultation at the end of May 2020, Ms. Berruyer's clinical presentation was typical for an adult patient with $\mathrm{AD}$. She had chronic eczema localised on the hands, head and neck, and diffuse flares. The severity of the eczema was moderate, but $\mathrm{AD}$ was having a major impact on her quality of life. Ms. Berruyer was also suffering from rhinoconjunctivitis due to pollen.

It is noteworthy that Ms. Berruyer had her first consultation during the lockdown due to the COVID-19 pandemic, and the flares on her hands and her face were probably related to stress. Worsening of chronic inflammatory dermatoses (e.g. $\mathrm{AD}$, psoriasis and urticaria) has been observed during lockdown [12], particularly in connection with stress (e.g. sudden change in work and lifestyle habits). Inflammation can also be activated by the skin occlusion and friction associated with wearing a mask, repeated handwashing and the use of hydroalcoholic sanitising solution on damaged hands.

The first step in Ms. Berruyer's treatment was to explain the disease to her, re-explain the topical care modalities, specifically how to apply topical corticosteroids and optimise their effect [13]. However, topical corticosteroids were not sufficient to halt the flares that were 
Table 1 How can you optimise the management of your patient?

Re-explain topical care procedures

How to properly apply topical corticosteroids [13]

Propose alternatives to scratching

Wet-wrap therapy with topical corticosteroid can be recommended for patients with moderate to severe AD to decrease the severity of disease [or itching, as appropriate] and water loss during flares [14]

Consider the alternatives to scratching (foam ball, massage roller, Velcro®) to calm itching

Offer a therapeutic education programme

Educational programmes, video training or nurse-led workshops make it possible to identify patients' problems on specific themes, and encourage exchanges between patients about their experience of the disease

Refer to patients' associations

Several sites (e.g. www.fondation-dermatite-atopique.org, https://www.dermatite-atopique.fr/ or https://nationaleczema. org/) providing resources, such as testimonials from other patients, and lists of specialists by region

having a strong impact on Ms. Berruyer's mood, so I suggested systemic treatment. As Ms. Berruyer is young and healthy, ciclosporin was proposed as the first treatment option to interrupt the flares and induce a rapid improvement. I also treated her for a palpebral rash, a rosacea frequently seen in young, fair-skinned women.

Ms. Berruyer responded very well to this treatment, with a $75 \%$ regression of lesions within 1 month, and no clinical side effects at that time. The primary benefit for her was the improvement in her quality of life. Renal side effects appeared after 6 months of ciclosporin treatment, with an increase in serum creatinine. I had warned Ms. Berruyer that ciclosporin is not a long-term treatment. She understands that the first goal was to rapidly interrupt the flares and that she would probably need another treatment in the long term. Thus, our current goal is to gradually decrease the dose of ciclosporin and introduce dupilumab as a long-term replacement. As Ms. Berruyer has very localised chronic $\mathrm{AD}$ (hands and face), we also plan to perform patch tests to eliminate contact eczema as an exacerbating factor. These tests cannot be carried out while Ms. Berruyer is on ciclosporin as they will be less effective.

Ms. Berruyer's medical history is typical for AD. Since childhood, she has seen numerous general practitioners and specialists, often received the same treatment without clear explanation, and has only received appropriate care for her condition at a late stage of the disease. General practitioners and paediatricians must be aware that $\mathrm{AD}$ flares or severe eczema should be considered as medical emergencies, and that a baby with $\mathrm{AD}$ should be referred quickly for a dermatology consultation. Unfortunately, many patients suffering from AD that has been evolving since birth leave the healthcare system, and may consider alternative medicine and/or practise self-medication. Therefore, reintegrating patients with $\mathrm{AD}$ into the healthcare system is a key step to enable them to benefit from treatments that are best suited to their conditions. They should be given the opportunity to benefit from advances in the available treatments.

As healthcare professionals, we have a primary duty of care to our patients. It is important that we take the time to explain the disease to them and precisely explain how to manage home remedies. Listening and reassuring are the keys to establishing a relationship with the patient and providing good care. It takes time, in the initial consultation and during follow-up, but it is important to understand the patient's expectations and treatment objectives, and ensure that the treatment is tailored to the individual's comorbidities, personal preferences 
and lifestyle. In recent years, several systemic therapies have been introduced in the field of $\mathrm{AD}$, and patients who have just been diagnosed with $\mathrm{AD}$ (and/or parents of diagnosed children) should know that effective treatments are available today for this chronic disease.

\section{ACKNOWLEDGEMENTS}

Funding. This commentary and Rapid Service Fee were funded by Sanofi, France.

Authorship. All named authors meet the International Committee of Medical Journal Editors (ICMJE) criteria for authorship for this article, take responsibility for the integrity of the work as a whole, and have given their approval for this version to be published.

Medical Writing and/or Editorial Assistance. We thank Pierre-Alain Boyer, PhD, for medical writing assistance on behalf of Springer Healthcare, France. Institutional support for editorial assistance from Springer Healthcare, France, was provided by Sanofi.

Disclosures. Dr. Delaunay has acted as a consultant and speaker for Sanofi, AbbVie, Lilly, Leo pharma and Janssen; Ms. Berruyer has nothing to disclose.

Compliance with Ethics Guidelines. This article is based on previously conducted studies and does not contain any new studies with human participants or animals performed by any of the authors.

Data Availability. Data sharing is not applicable to this article as no datasets were generated or analyzed during the current study.

Open Access. This article is licensed under a Creative Commons Attribution-NonCommercial 4.0 International License, which permits any non-commercial use, sharing, adaptation, distribution and reproduction in any medium or format, as long as you give appropriate credit to the original author(s) and the source, provide a link to the Creative Commons licence, and indicate if changes were made. The images or other third party material in this article are included in the article's Creative Commons licence, unless indicated otherwise in a credit line to the material. If material is not included in the article's Creative Commons licence and your intended use is not permitted by statutory regulation or exceeds the permitted use, you will need to obtain permission directly from the copyright holder. To view a copy of this licence, visit http://creativecommons.org/licenses/by$\mathrm{nc} / 4.0 /$.

\section{REFERENCES}

1. Guttman-Yassky E, Nograles KE, Krueger JG. Contrasting pathogenesis of atopic dermatitis and psoriasis-part I: clinical and pathologic concepts. J Allergy Clin Immunol. 2011;127:1110-8.

2. Schuttelaar ML, Kerkhof M, Jonkman MF, et al. Filaggrin mutations in the onset of eczema, sensitization, asthma, hay fever and the interaction with cat exposure. Allergy. 2009;64:1758-65.

3. Fedenko ES, Elisyutina OG, Filimonova TM, et al. Cytokine gene expression in the skin and peripheral blood of atopic dermatitis patients and healthy individuals. Self Nonself. 2011;2:120-4.

4. Nomura T, Honda T, Kabashima K. Multipolarity of cytokine axes in the pathogenesis of atopic dermatitis in ters of age, race, species, disease stage and biomarkers. Int Immunol. 2018;30:419-28.

5. Richard MA, Corgibet F, Beylot-Barry M, et al. Sexand age-adjusted prevalence estimates of five chronic inflammatory skin diseases in France: results of the «OBJECTIFS PEAU» study. J Eur Acad Dermatol Venereol. 2018;32:1967-71.

6. Silverberg JI. Comorbidities and the impact of atopic dermatitis. Ann Allergy Asthma Immunol. 2019;123:144-51.

7. Brunner PM, Silverberg JI, Guttman-Yassky E, et al. Increasing comorbidities suggest that atopic dermatitis is a systemic disorder. J Invest Dermatol. 2017;137:18-25.

8. Misery L, Seneschal J, Reguiai Z, et al. Patient burden is associated with alterations in quality of life in adult patients with atopic dermatitis: results from 
the ECLA Study. Acta Derm Venereol. 2018;98: $713-4$.

9. Xu YC, Wang JP, Zhu WJ, Li P. Childhood atopic dermatitis as a precursor for developing attention deficit/hyperactivity disorder. Int J Immunopathol Pharmacol. 2020. https://doi.org/10.1177/ 2058738420962902.

10. Wollenberg A, Barbarot S, Bieber T, et al. Consensus-based European guidelines for treatment of atopic eczema (atopic dermatitis) in adults and children: part II. J Eur Acad Dermatol Venereol. 2018;32:850-78.

11. Wollenberg A, Barbarot S, Bieber T, et al. Consensus-based European guidelines for treatment of atopic eczema (atopic dermatitis) in adults and children: part I. J Eur Acad Dermatol Venereol. 2018;32:657-82.

12. Giacalone S, Minuti A, Spigariolo CB, Passoni E, Nazzaro G. Facial dermatoses in the general population due to wearing of personal protective masks during the COVID-19 pandemic: first observations after lockdown. Clin Exp Dermatol. 2020. https:// doi.org/10.1111/ced.14376.

13. Habif TP, Campbell J, Chapman S, Dinulos J, Zug K. Maladies cutanées: diagnostic et traitement. Amsterdam: Elsevier; 2008.

14. Devillers AC, Oranje AP. Wet-wrap treatment in children with atopic dermatitis: a practical guideline. Pediatr Dermatol. 2012;29:24-7. 